\title{
Effect of Venture Capital Financing on Investment in Kenya
}

\author{
Valerie Kizito ${ }^{1}$ and Kevin Wanjala ${ }^{2 *}$ \\ ${ }^{1}$ The University of Nairobi, Kenya \\ ${ }^{2}$ Egerton University, Kenya \\ *Corresponding Author: wanjalakevin89@gmail.com \\ https://riiopenjournals.com/index.php/business-perspective-review/index
}

Doi: https://doi.org/10.38157/business-perspective-review.v2i1.119

Citation: Kizito, V. \& Wanjala, K. (2020). Effect of Venture Capital Financing on Investment in Kenya. Business Perspective Review, 2(1), 45-60. Doi: https://doi.org/10.38157/business-perspective-review.v2i1.119

\section{Research Article}

\begin{abstract}
Purpose: The objective of this paper is to determine the effect of venture capital financing on investment in Kenya.

Methodology: To achieve the objective of the study, venture capital was disaggregated into two variables, namely, the number of firms financed and the total amount of financing. Other variables, such as interest rate and GDP per capita were also included in the analysis to act as control variables. The study used 10 years of data spanning from 2009 to 2018. A regression analysis was done in order to analyze the data.

Results: The study established that there is a positive correlation between the number of firms financed and the aggregate investment in Kenya. The study observed that the total amount of financing has a positive correlation with aggregate investment.

Implications: The study concludes that venture capital financing has a positive effect on aggregate investment levels in Kenya. The study recommends that the Kenyan government should come up with ways of financing small and medium enterprises, which will boost their productive capacities leading to more investment in the country and more generation of income.
\end{abstract}

Keywords: Venture Capital Financing, Investment, Firms, Kenya.

\section{Introduction}

In a country, the government of the day is entrusted with steering economic growth. Previously, governments employed economic measures which were expected to have a positive impact on the population but in the long run, it failed to improve the lives of the majority of the population. Large industries were set up to provide employment and improve the living standards of its employees, little change was affected (White Paper on International Development, 2000). Consequently, the governments had to turn their attention to other 
emerging sectors such as small-scale enterprises in hopes of spurring economic growth. Small and Medium Enterprises (SMEs) promote competition, innovation, and enhance the culture necessary for private sector development and industrialization (Memba, 2015).

Unfortunately, SMEs lack access to credit which hinders their emergence and growth. Poor access to formal finance is mainly because of the high risk of default among SMEs and inadequate financial facilities (Kauffmann, 2005). Without proper financing, SMEs can neither expand to compete globally nor can they acquire technology or meet their fixed and working capital requirements (Wanjohi \& Mugure, 2008). Venture capital emerged to fill the void by providing equity capital to SMEs in order to enhance growth. The venture capital industry embraces opportunities that create value based on rational partnerships with a less formal control mechanism and a limited track record.

Venture capital is defined as equity or equity-linked investments in new, privately held companies, where the investor is a financier who typically acts as a director, a manager, and an advisor of the firm (Kortum \& Lerner, 2000). According to, Gompers and Lerner (2001), venture capital is an independent, professionally managed, dedicated pool of capital that focuses on equity or equity-linked investments in privately held, high growth companies. It is an investment in a growing SME or start-up with high growth prospects that is facilitated by a Venture Capitalist who manages funds raised from public and private investors. When an entrepreneur is unable to acquire bank financing because of the businesses' high-risk venture capital financing is sort after as an alternative. Venture capital financing provides equity to promising small businesses in exchange for an equity stake in the business.

Notably, venture capital investment is a non-bank financial option that is prevalent in developed financial markets for start-up or small firms (Keuschnigg 1998). SMEs emergence and eventual growth is hampered by the difficulty in accessing financing, therefore, restricting their options to debt financing or equity. Because of their small size, high risk of default and poor financial structures these companies are unable to qualify for loans from financial institutions.

Venture capital also helps investors to access equity capital as a source for finance in cases of expansion of the business while still maintaining control. In line with the venture capital financing agreement, the investor firm will provide funds to enable an enterprise to operate and in return, it gets an ownership stake in the enterprise (Boateng, 2010). Normally, venture capitalists look for features such as competitive edge, growth potential, competent management, and other intangible factors (Smart, Megginson \& Gitman, 2004).

Fairchild (2009), reported that an entrepreneur prefers choosing a venture capitalist because of their preference to financiers with value-creating abilities. The extensive relationship and expertise of the venture capitalist not only adds value to the business but it also increases customer credibility. In return, the enterprise gains access to the venture capitalist knowledge in budgeting, accounting, back-office operations, and computer systems (Amissah, 2009).

Venture capital investment has been demonstrated to contribute to the graduation of many enterprises from small, to medium and finally to macro enterprises, as well as, increased productivity of the beneficiary firms. The great achievement of venture capitalists has been 
primarily linked to their role in connecting a set of entities such as investment banks, government agencies, universities, and large corporations. The intricate set of an overlapping network allows them to gain access to market information including risks related to enterprise development, this ensures the elimination of information asymmetry and consequently, the survival of new businesses. Baeyensand Manigart (2003) asserts that venture capitalists screen potential investments by collecting information about the business on its market approach, management team or entrepreneur, to increase investment while reducing the initial information asymmetry and potential problems with entrepreneurs.

Venture capitalists are responsible for raising funds and investing those funds in an investment process owned by an entrepreneur. Furthermore, venture capital investors participate in the management of their investment applying their vast knowledge in business to ensure growth. Silvola (2008) reports that venture capital investors have great power over several areas of business, including strategic decisions, business development, and management control. Also, venture capital investment has the responsibility of stimulating further venture capital investment through co-investment with corporations. According to Peneder (2010), individual investors organize into fund management groups to share research and pool their investment capital to invest in entrepreneurial financing. Therefore, entrepreneurial financing acts as a substitute for domestic investment in countries where domestic investors are not well established or afraid to take risks (Megginson, 2001).

\section{Venture Capital Financing and Investment in Kenya}

Kenya has positioned itself as the economic hub of the East African region; this has mainly been attributed to its relatively stable regulatory frameworks, sophisticated business environment, a functional electronic banking system, large and enlightened human capital, and a dominant private sector-led economy. Consequently, Kenya has attracted numerous equity investors and venture capital investors in the last decade, making it the third country, after South Africa and Nigeria regarding the capital venture and private equity transactions in Sub Saharan Africa. Between 2013 and 2015 alone more than \$750 million venture capital funds have been invested across 60 percent of early-stage enterprises businesses in Kenya (Divakran, McGinnis \& Schneiderrking, 2018).

In Kenya, primary sources of capital for venture capital investors are foreign development finance institutions (DFIs), high net worth individuals (HNWs) and foreign institutional investors. DFIs strong participation in the market is because of their longstanding participation as investors to emerging markets. Further, they provide governance, social, and environmental best practices while serving as a training ground for the human capital (Divakran, McGinnis \& Schneiderrking, 2018). IFC and CDC are the most active DFIs in the East Africa region each having made both direct investment and fund investment as part of their overall investment. DFIs can act as a source of co-investment capital for venture capital funds because of their significantly more sources of stock capital. In Kenya DFIs that invest directly in companies include IFC, CDC, Proparco, DEG Norfund, and FMO. (Divakran, McGinnis \& Schneiderrking, 2018). Family offices are High net worth individuals that represent an important source of 
potential investment for venture capital. In Kenya, foreign HNWs outnumber Kenyan families, although the minimum investment of US $\$ 1$ million usually required by private equity funds limits the addressable market in the country.

Also, there has been some investment by institutional investors and sovereign wealth funds (SWF) although most of their capital is directed toward Pan African and not regional or national funds. Recent reports have suggested that large SWFs that are active in private equity such as Singapore's GIC and Abu Dhabi Investment Authority (ADIA) have included Africa in their investment plans. Kenyan private equity firms, such as Catalyst, report receiving investment from US-based funds of funds.

In Kenya, DFIs and international investors have been the most crucial LPs and perhaps the most consistent source of venture capital and private equity funds for entrepreneurs. However, venture capital and private equity should be sourced from local domestic institutional investors because of their fundraising potential that can play a major catalytic role. Notable examples of institutional investors in local funds include Ascent Capital which raised more than $\$ 80$ million for its inaugural Ascent Rift Valley Fund, Nation Media Group Pension Fund, and Kenya Power Pension Fund contributed a combined sum of $\$ 5$ million. Institutional investors are a fundamental cog to the growth of the venture capital and private equity sector in Kenya. Even though most local institutions in the emerging market regions trail foreign investors in the

private equity fund sector they can evolve into core investors in the assets class. Local institutional investors are critical to creating a domestic market for fundraising because of their size and need to generate long-term returns.

\section{Research Problem}

Several empirical studies have tried to establish a link between venture capital financing and survival of the early enterprise, (Lerner, 2002; Dessí, 2009; Dessí \& Yin, 2010; Haeussler, Harhoff \& Müller, 2009). However, little is known about whether venture capital financing has any impact on private investment in a country. Additionally, literature has pointed out venture capital financed firms have demonstrated better financial performance than non-venture capital-funded firms (Megginson \& Weiss, 1991; Jain \& Kini, 1995); Hellmann \& Puri, 2000); Kaplan \& Lerner, 2010). It is worth noting however, that the process of selecting firms for venture capital financing is vigorous and very competitive that only the best funds are selected and funded. In essence, these firms are smaller in number compared to the ones that are left out. Locally, studies have also concentrated on venture capital and performance of firms and no research has been conducted on venture capital financing and aggregate investment nexus despite the fact that the existence of such as a study may be crucial for designing best policies for investment. Notable among the studies conducted include: (Njoroge, 2003; Memba; 2015; Kiprotich, 2017; \& Njumbi, 2018). It is against this background therefore that this study sought to answer the question, what is the effect of venture capital financing on investment in Kenya? 


\section{Literature}

The literature highlights various existing theories and studies that form the foundation of this study.

\subsection{Theoretical Literature}

The section gives a review of theories that relate to venture capital that applies to the investment. This study will be based on agency theory.

\subsubsection{Agency Theory}

The agency model is considered as one of the oldest theories in the literature of management and economics (Daily, Dalton, \& Rajagopalan, 2003; Wasserman, 2006). Ross (1973) and Mitnick (1975) have had the most notable influence in shaping the theory of agency. Though the central idea behind each of their theories remained similar, they each had different regard to the agency problem. Ross (1973), saw it as an incentives problem while Mitnick (1975), considered that the problem is caused by the institutional structure. Hence, the theory attempts to solve the agency problem which occurs when the goals of the principal (Venture Capitalist) and agent (entrepreneur) are different, and when it is difficult for the principal to know what the agent is actually doing. Sapienza and Gupta (1994), described a situation where entrepreneurs and investors disagree on the ways to achieving their objectives and termed this type of agency problem as good faith disagreements.

Mitnick (1975), explains that the institutional approach plays a part in developing the core agency theory and it is designed to understand the behavior of the real world. His theory posits that institutions are built around agency and grow to reconcile with the agency. As a result, institutional venture capitalists are easier to locate, more visible, and have more resources to invest in entrepreneurship. Typically, entrepreneurs start businesses with an innovative base with the expectation that the firm will become a long-term success. The new enterprise obtains some venture capital financing to aid its development (Mason \& Harrison, 1996).

According to Eisenhardt (1989), agent theory assumes that both the agent (entrepreneur) and principal (venture capitalist) are self-interested and have bounded rationality. The bounded rationality by each actor (venture capitalist and entrepreneur) gives rise to information asymmetry between the parties (Amit et al., 1990). Information asymmetry occurs when one party of a contract is privy to relevant information not available to the other party of the contact (Panwar, 2005). Note, when the goals of the Venture Capitalist and entrepreneur are aligned, there is no agency problem (Eisenhardt, 1989).

Interestingly, recent research has failed to find much relevance of agency theory in explaining the venture capitalist and entrepreneur relationship (Kelly \& Hay, 2001). In cases where there is an agency problem then there is goal incongruence between the two parties meaning their goals have not been aligned (Arthurs \& Busenitz, 2003). Note, to reduce chances of agency problem agents (entrepreneurs) need to ensure a change in opportunity behavior and avoid tensions with their principle (Venture Capitalist). In entrepreneurship, literature agency theory has emerged as the dominant theory in explaining the venture capital and entrepreneur relationship 
(Amit et al., 1990). The theory has for years been the dominant theoretical perspective applied to the venture capitalists and entrepreneur relationship.

\subsubsection{Resource Dependency Theory}

Pfeffer and Salancik (1978), formulated the resource dependency theory which posits that organizations that have resource scarcity because of their smaller organizational size are more inclined to formally collaborate. Organizations with a larger resource base indicated by their huge annual budget size are less inclined to formally collaborate. The theory implies that to understand organizational behavior, one ought to understand how organizations and other social actors in the environment relate. Often, organizations either comply with the demands of others, or they manage dependencies that create limitations on organizational actions. An entrepreneur with scarce resources would look to collaborate with a more established organization or individual (venture capitalist).

According to Davis \&Cobb, (2010), scholars investigating power in organizations are very likely to draw on the resource dependency theory. Organizations form alliances with each other for longevity, knowledge, and resource sharing. These alliances are guided by agreements among organizations to explore joint objectives through the sharing of resources or knowledge and coordination of activities (Scott and Davis, 2007). Typically, businesses need resources to survive hence they need to interact with other businesses that control these resources. Eisenhardt (2009), posits that there is a renewed interest in the resource dependence theory and offers suggestions on where it might be heading.

Nonetheless, there are a number of opposing opinions to the basic tenets put forth by the theory. In opposing the theory, Subramanian et al., (2009), through his comparative study of literacy and immigration established that correlation at the group level does not need to apply at the individual level. In a study of entrepreneurial ventures in US technology-based industries, Katila et al (2008), examines the conditions under which entrepreneurship are likely to be part of a corporate investment relationship. The entrepreneur's fundamental tension underlying the decision to take up venture capital is the tradeoff between the potential of being taken advantage of and access to resources. Entrepreneurs enter corporate investment relationships when managerial resources needed are great and when financial needs are high (Katila et al., 2008). While these works offer an excellent starting point, it seems there are numerous opportunities for scholarly contribution to resource dependences theory. In the meantime, assumptions are being tested alternative strategies are being offered and gaps in the theory are being filled (Katila et al., 2008).

\subsection{Empirical Studies}

A number of studies have been conducted in the area of venture capital and investment but with varied results and conflicting outcomes about the possible effect of venture capital on investment. According to Dobloug (2008), the provision of reliable capital and management expertise to those firms leads to shorter times-to-market through accelerated growth, and more solid development of company structures in the areas of marketing, strategy and market 
positioning. The fact is that this kind of financing played no little part in the evolvement and increasing market strength of technological sectors, especially in the US (Gompers \& Lerner, 2001).

As technological sectors rely heavily on innovativeness to stay competitive, it is useful to investigate the particular impact of venture capital funding on investment. However, finding empirical evidence for detailed explanations of this relationship and involving factors to prove the impact on outcomes appeared to be difficult (Gompers and Lerner, 2001). Nevertheless, three studies by different researchers move to the foreground as they are considered to be important in this case. The first research to be taken into account has been carried out by Kortum and Lerner (2000). The research covered data of three decades about companies and their accompanying patenting patterns across twenty industries and related venture capital investments on the industry level. The assumption was that venture capital investments might disproportionally affect the evolvement of innovations and therefore hampering investment in the long-run. Contrary to the assumptions however, the outcome of the study suggests a strong positive correlation between venture capital funding and investment.

Another research to be considered is the study conducted by Hellmann and Puri (2000), which covered data by a questionnaire within a small sample in Silicon Valley, included also nonventure-backed companies to present possible differences in VC-funding and their consequences. According to this, firms who follow a more innovative strategy on average achieve funding earlier in their business life cycle and have higher chances of obtaining venture capital investments. This has already been assumed earlier as VC's mainly target highly innovative companies as they use to have better economic prospects. Moreover, VC-backed companies strengthen the assumption made by Dobloug (2008) of a faster time-to-market and perceived VC-funding as an advantage, especially for companies with a focus on innovations. Although findings share partial similarities with the previous research by Kortum and Lerner (2000), concerns about the insufficiency of obtained results can here be addressed to the small sample size of fewer than 200 firms. Additionally, it has not been proofed in this research whether VC-funding facilitates higher investment through innovation or companies already featuring high innovativeness choose venture capital as the best opportunity for financing further activities.

The third research the study focuses on is a study by Hirukawa and Udea (2006) who took the study by Kortum and Lerner (2000) as a base and adapted it to a larger timeframe and used fiveyear averages of existing data to cover for differences in capacity utilization of variables. Additionally, they included another measure of innovational impact, namely TFP (Total Factor Productivity) and Labor Productivity Growth. As opposed to Kortum and Lerner's research, they tried to measure and explain productivity growth by the rate of R\&D intensity when determining the influence of VC-investments on TFP. However, this model did not lead to significant outcomes and could not support the assumption of a VC influence on Total Factor Productivity. Nevertheless, testing Labor Productivity growth showed more significant indications as the factor labor is subject to higher adjustability when inputs increase. Still, concerns were also addressed as it is just a partial and vulnerable measure of total productivity 
since an increase in labor productivity not always entail an increase in total productive efficiency. As a result of their modeling, the study established a negative correlation between venture financing and innovation.

\section{Methodology}

\subsection{Research Design}

This study used a causal research design to investigate the effect of venture capital financing on investment in Kenya. Using aggregate national data, the study covered a period of 10 years that is from 2008 to 2018. It focused on the aggregate investment and venture capital financing in Kenya.

\subsection{Data Collection}

The study relied on secondary data. Annual data was collected from various sources covering the period 2008 to 2018. Data on venture capital financing was collected from the Capital Markets Authority as it is the one that licenses the venture capital financing and keeps the records of all the financing. Other macro-economic data were collected from the Central Bank of Kenya, and the Kenya National Bureau of Statistics.

\subsection{Diagnostic Tests}

Time series analysis is mainly based on the Ordinary Least Square assumptions. The study conducted a normality test to check the distribution of the data, using skewness and Kurtosis tests. The ordinary least square requires the regression model to be normally and identically distributed, with a mean of zero and a constant variance.

OLS requires that the independent variables in the model should not be correlated, an assumption violation of which may result in the problem of multicollinearity that will render the inferential tests insignificant. Therefore, a multicollinearity test was also conducted using the White general test. The study carried out tests for heteroscedasticity and autocorrelation to check the validity of the model. Heteroscedasticity refers to a situation that arises when the variance of the error term is not constant. It results in the violation of Ordinary Least Square (OLS) which requires the error term to have a constant variance, this is likely to lead to inefficient regression predictions. The study used the Bresuch- Pagan test.

On the other hand, Autocorrelation is an econometric problem that arises when two successive error terms seem to be correlated, a situation also referred to as serial correlation. Ordinary least square requires that error terms in a time series be independent of each other as this would lead to biased and inconsistent estimates rendering the inferences invalid. The study used the Breusch-Godfrey LM test for autocorrelation. The linearity of the model is also an important test that needs to be conducted. However, this was done by the researcher by ensuring that all the variables are only raised to power one. 


\subsection{Data Analysis}

In order to find out the effect of venture capital financing on investment in Kenya, the study used the Ordinary Least Square framework in the analysis. The dependent variable was the aggregate investment, while the independent variable included two measures of venture capital financing, that is, the amount of money financed and the number of firms financed. The model also included other control variables which are essential determinants of investment that is, interest rate, and GDP per capita. The functional form of the model is:

$A I=F(N F F, T A F, I R, G D P P C$,

Shahbaz (2012) Log-log model was used so as to provide more efficient results and may eliminate or reduce heteroscedasticity. The parameters of the log-log model have an interpretation as elasticity and constant elasticity is assumed overall values of the data set.

$I n A I_{t}=\beta_{0}+\beta_{1} I n N F F_{t}+\beta_{2} I n T A F_{t}+\beta_{3} I n I R_{t}+\beta_{4} G D P P C_{t}+\varepsilon_{t} \ldots \ldots \ldots \ldots \ldots .2$

Where:

$\mathrm{AI}=$ Aggregate Investment

$\mathrm{NFF}=$ Number of Firms Financed

TAF=Total Amount of Financing

IR=Interest Rate

GDPPC $=$ GDP per capita

$\varepsilon-$ Error term

$\beta_{0}=\mathrm{Y}$ intercept

$\beta_{1} \beta_{2}, \beta_{3}, \beta_{4}$, and $\beta_{5}$ are partial slope coefficients

\subsection{Justification of the Variables}

\subsubsection{Venture Capital Financing}

A number of studies have linked venture capital financing to investment. Prowse (1998), asserts that venture capital financing has played a critical role in contributing to investment activities in a country. The study attempted to explain the mechanism through which venture capital contributes to investment. Firstly, they point out that, through innovation financed firms can diversify into other products and increase their line of production which leads to mass-scale production. Additionally, they established that venture capitalist do not only fund an organization but also bring in their expertise in various types of management transforming risky start-ups to stable ones, thereby leading to stability of firms in the different industries. Ewing and Butler (2007) also noted that venture capital has played a pivotal role on investment in a nation, through a critical mechanism of channeling capital through the national and international markets, leading to availability of funds and reduction of interest rates which would otherwise be higher if firms were only depending on debt financing.

\subsubsection{Interest Rate}

There is a general consensus among monetary and economic scholars about the impact of interest rate on investment. The interest rate has been established to be the major determinant of 
investment as it plays a critical role in determining the cost of capital. The current interest rate is not only important in explaining the current investment but also predicting future investment by adjusting saving (Ibicioglu \& Kapusuzoglu, 2012). Alvarez (2010) notes that an increase in the rate of interest would result in a decrease in the price of bonds and a fall in interest rate would lead to an increase in binds prices. In this regard, interest rate plays a major influence on the scale of investment as it operates as an opportunity cost of investment to total investment. If investment incomes remain constant, then an increase in interest rates would result in an increase in investment cost. This would then lead low-income investors to pull out from investment thus reducing demand for investment. On the other hand, a reduction in interest rate would facilitate a reduction in investment cost thus stimulate investment in a country (Sax, 2010).

\subsubsection{Gross Domestic Product Per Capita}

Literature has pointed out the importance of GDP per capita in influencing investment in a country. According to a 2016 World Bank report, GDP per capita is a key indicator for measuring the level of people's income in a nation. A rise in GDP per capita can, therefore, be interpreted as the rise in levels of income, this would provide an incentive for people to save increasing the aggregate saving in a country. Keynes (1936) pointed out that there is a savings investment nexus, and that the two variables exhibit an increasing return to scales. An increase in income would lead to an increase in saving which would lead to an increase in investment in a country.

\section{Results}

This chapter presents pre-estimation diagnostic tests such as unit root test and cointegration test, the regression model, and as well as the post-estimation diagnostic tests.

\subsection{Unit Root Test}

Unit root testing is critical in time series modeling as it helps in avoiding the possible cases of spurious regression. This study used Phillips Peron and the Augmented Dickey-Fuller approach to test for the presence of unit root. The two approaches were used for the sake of robustness. The results for the unit root test are presented in Table 1.

Table 1: Unit Root Test

\begin{tabular}{|c|c|c|c|c|c|}
\hline \multirow[t]{2}{*}{ Variables } & \multicolumn{2}{|c|}{ ADF Test Z(t) } & \multicolumn{2}{|c|}{$P P$ test $\mathrm{Z}(\mathrm{t})$} & \multirow{2}{*}{$\begin{array}{c}\text { Order of } \\
\text { Integration }\end{array}$} \\
\hline & At level & First Difference & At level & First Difference & \\
\hline LnAI & -1.972 & $-3.227^{* * *}$ & -2.804 & $-3.321^{* * * *}$ & I (1) \\
\hline LnNFF & -0.525 & $-3.208^{* * *}$ & -0.023 & $-3.707^{* * *}$ & $\mathrm{I}(1)$ \\
\hline LnTAF & -2.148 & $-4.801^{* * *}$ & -2.092 & $-6.970^{* * * *}$ & I (1) \\
\hline LnIR & -1.294 & $-3.709^{* * *}$ & -1.315 & $-3.706^{* * * *}$ & I (1) \\
\hline LnGDPPC & -0.173 & $-6.569^{* * *}$ & -0.137 & $-6.195^{* * *}$ & $\mathrm{I}(1)$ \\
\hline
\end{tabular}

Note: ${ }^{* * *}$ denotes significant at 1 percent 
From the results presented in Table 1, all the variables contain a unit root, therefore they were differenced once to get rid of the unit root. The variables in the study can, therefore, be said to be integrated of order one.

\subsection{Regression Analysis}

The study employed regression analysis using the differenced data since all the variables were integrated of order one. The regression analysis results are presented in Table 2 and Table 3

Table 2: Model Summary

\begin{tabular}{|cc|}
\hline R-squared & 0.9165 \\
\hline Adj R-Squared & 0.8497 \\
\hline F-statistics & $\mathrm{F}(4, \quad 5)=13.72$ \\
& Prob $>$ F $=0.0066$ \\
\hline
\end{tabular}

Table 2 shows the summary statistics for the regression model. The coefficient of determination of the model is 0.9165 meaning that 91.65 percent of the variation in the model is explained by the included independent variables namely, the number of firms financed. These results indicate the model is a good fit. The F statistics of the model are 13.72 and the P-value is 0.006 , this shows that the model is suitable in predicting the population parameter.

Table 3: Regression Results

\begin{tabular}{|lllll|}
\hline Variables & Coefficients & Standard Errors & T-statistic & P-value \\
\hline Constant & 19.5885 & 1.3475 & 14.54 & 0.000 \\
LnNFF & 0.5813 & 0.1048 & 5.06 & 0.000 \\
LnTAF & 0.1367 & 0.0199 & 6.88 & 0.000 \\
LnIR & -0.1810 & 0.0256 & -7.1 & 0.000 \\
LnGDPPC & 0.6410 & 0.1467 & 4.37 & 0.005 \\
\hline
\end{tabular}

Table 3 above shows the regression results. The Y-intercept is 19.5885. The partial slope coefficient of the number of firms financed is 0.5885 , the results indicate that a 10 percent increase in the number of financed firms would lead to a 5.85 percent increase in the level of aggregate investment. These results are consistent with the works of Ewing and Butler (2007) who established that the number of firms by venture capitalists has a positive effect on aggregate investment. Financed firms can afford to be more innovative and thereby increasing their line of production leading to a mass scale of production.

The partial slope coefficient for the total amount of financing is 0.1367 and it is significant at 1 percent. The result indicates that a 10 percent increase in the total amount of financing would result in a 1.36 percent increase in the level of aggregate investment. These results are consistent with the works of Prowse (1998) who found that the amount of financing to be having a positive effect on aggregate investment. Venture capitalists do not only fund an organization but also bring in their expertise in various types of management transforming risky start-ups to stable ones, thereby leading to stability of firms in the different industries.

The partial slope coefficient for the interest rate is -0.181 and this is statistically significant at 1 percent. The results show that a 10 percent increase in the interest rate would lead to a reduction in the level of investment and vice-versa. The results conform to the accelerator

55 Published by Research \& Innovation Initiative, 3112 Jarvis Ave, Warren, MI 48091, USA 
theory of investment as well as empirical literature. Ibicioglu and Kapusuzoglu (2012) assert that the current interest rate is not only important in explaining the current investment but also predicting future investment by adjusting saving. An increase in the rate of interest would result in a decrease in the price of bonds and a fall in interest rate would lead to an increase in binds prices. In this regard, interest rate plays a major influence on the scale of investment as it operates as an opportunity cost of investment to total investment. If investment incomes remain constant, then an increase in interest rates would result in an increase in investment cost. This would then lead low-income investors to pull out from investment thus reducing demand for investment. On the other hand, a reduction in interest rate would facilitate a reduction in investment cost thus stimulate investment in a country

The partial slope coefficient for Gross Domestic Product per capita is 0.6410 and it is statistically significant at 5 percent. These results show that a 10 percent increase in Gross Domestic Product per capita would lead to a 6.41 increase in the aggregate investment in Kenya. The results are in line with the Keynesian theory which postulated that a rise in GDP can be interpreted as the rise in levels of income, this would provide an incentive for people to save increasing the aggregate saving in a country. The theory further posits that out that there is a savings investment nexus, and that the two variables exhibit an increasing return to scales. An increase in income would lead to an increase in saving which would lead to an increase in investment in a country.

\subsection{Post-estimation Diagnostic Tests}

Post estimation tests were conducted including to ensure that the model was robust. Lagrange multiplier test for autocorrelation, and Breusch-Godfrey for heteroscedasticity. The results are displayed in Table 4

\section{Table 4: Post Estimation Tests}

\begin{tabular}{|cc|}
\hline Test & Coefficient \\
\hline Breusch-Godfrey LM test for autocorrelation & Chi $^{2}=0.423$ \\
& Prob $>$ chi $2=0.5156$ \\
\hline $\begin{array}{c}\text { Breusch-Pagan / Cook-Weisberg test for } \\
\text { heteroskedasticity }\end{array}$ & Chi $^{2}=0.327$ \\
Prob $>$ chi2 $=0.618$ \\
\hline
\end{tabular}

Table 4 shows the results for post estimation diagnostic tests. Among the tests conducted was the Breusch-Godfrey LM test for autocorrelation. The null hypothesis for this test states that there is no serial correlation while the alternative hypothesis states that there is serial correlation in the error term. Form the findings, the Chi-square coefficient is 0.423 and the P-value is 0.5156 , meaning that it is not significant at any statistical level. We, therefore, accept the null hypothesis of no serial correlation and conclude that the model does not violate the OLS assumption of autocorrelation.

On the other hand, the Breusch-Pagan/Cock-Weisberg test for heteroscedasticity. The null hypothesis for the test states that the variance of the error term is constant while the alternative hypothesis states that the variance of the error term is not constant. The Chi-square coefficient obtained for the test is 0.327 while the P-value is 0.618 meaning that we accept the null 
hypothesis and conclude that the variance of the error term in the model is constant. This model, therefore, does not violate the Ordinary Least Square assumption of constant variance.

\section{Conclusions and Recommendations}

The study attempts to find the effect of the number of firms financed on the aggregate investment in Kenya. The study established that there is a positive correlation between the number of firms financed and the aggregate investment in Kenya. When firms are financed, they can afford innovation and become able to diversify their products contributing to a large level of investment in the economy. The study also aims to determine the effect of the total amount of financing of firms on the aggregate investment in Kenya. The study established that the total amount of financing has a positive correlation with the aggregate investment. Additionally, the study found out that the total amount of financing by venture capitalists has a positive effect on aggregate investment in Kenya. Venture capital also plays a pivotal role in investment in a nation, through a critical mechanism of channeling capital through the national and international markets, leading to availability of funds and reduction of interest rates which would otherwise be higher if firms were only depending on debt financing.

The study recommends that the Kenyan government should create an enabling environment for venture capitalists in Kenya by giving them favorable tax rates and incentives as they are important in contributing to the level of investment in Kenya. Venture capitalists should increase the number of firms that they finance and incubate. The government should come up with ways of financing small and medium enterprises as this will boost their productive capacities leading to more investment in the country and more generation of income.

\section{Limitations and Suggestions for Future Studies}

The study focused on a 10-year period which is quite limited. Therefore, it is suggested that studies should be carried out using a longer period to enable measuring the long-run and shortrun effects. Also, the study used the general venture capital financing only. Future studies should focus on the various types of venture capital financing and attempt to determine which type has more effect on aggregate investment level.

Conflicts of Interest: The authors declare no conflict of interest.

Authors Contribution: Valerie Kizito conceived the study, collected data, and drafted the manuscript. Kevin Wanjala designed the contents of the study, performed the statistical analysis, and participated in the sequence alignment of the manuscript.

\section{REFERENCES}

Alvarez, L.H.R. (2010). Irreversible capital accumulation under interest rate uncertainty. Mathematical Methods of Operations Research, 72 (2), 249-271

Amit, R., J. Brander \& C. Zott (1998). Why do Venture Capital Firms Exist? Theory and Canadian Evidence. Journal of Business Venturing, 13, 441-466 
Business Perspective Review 2(1), 2020

Arthurs, A., \& Busenitz, H. (2003). Production, information costs, and economic organization. The American Economic Review, 62(5), 777-795.

Bertoni, F. \& Colombo, M. (2005), Value-adding by Venture Capital: a Survey of the Literature. Working Paper for PRIME Venture Fun project.

Bygrave, W.D. \&Timmons J.A. (1986). Venture Capital's Role in Financing Innovation for Economic Growth, Journal of Business Venturing, 1(5), 161-76.

Cooper, D. R., and Schindler, P.S. (2006). Business research methods (9the ed.) New York

Davis, G. F., \& Cobb, J. (2010). Resource Dependence Theory: Past and future. Research in the Sociology of Organizations, 28(1), 21-42.

Dessí, R. (2009). Contractual execution, strategic incompleteness, and venture capital. CEPR Discussion Paper.

Dessí, R., \& Yin. N. (2010). Venture capitalists, innovation quality, and rent extraction. Mimeo, Toulouse School of Economics.

Divakaran, S., McGinnis, P., \& Schneiderrking. (2018). Survey of the Kenyan Private Equity and Venture Capital Landscape. Policy Research Working paper No 8598

Dobloug, T.A. (2008). Venture capital and innovation. Høgskolen i Hedmark, 6 (4), 132-146

Eisenhardt, K. M. (1989). Agency theory: An assessment and review. Academy of Management Review, 14(1), 57-74.

Ewing, C., and Butler, R. 2007. Private equity 2006/07: Country Q \& A; South Africa. Johannesburg: Cliffe Dekker.

Florida, R. L., and M. Kenny (1988). Venture Capital-financed Innovation and Technological Change in the USA. Research Policy, 17 (2), 119-137

Gompers, P.A., \& Lerner, J. (2001). The Money of Invention: How Venture Capital Creates New Wealth. Cambridge: Harvard Business School Press

Greene, W. W. H. (2012). Econometric analysis 7th Ed. In Prentice Hall.

Haeussler, C., Harhoff, D., andMüller, E. 2009. To be financed or not, the role of patents for venture capital financing. CEPR Discussion paper.

Hellmann, T., \& Puri, M. (2000). The interaction between product market and financing strategy: the role of venture capital. Review of Financial Studies, 13(4), 959-984.

Hellmann, T., \& Puri. M. (2002). Venture Capital and the Professionalization of Start-Up Firms: Empirical Evidence, The Journal of Finance, 57 (1), 169-197.

Hirukawa, M. \& Ueda, M. (2008). Venture Capital, Innovation, and Investment: Which is first?. Working Paper No 08/123 Northern Illinois University and the University of Wisconsin.

Ibicioglu, M., \& Kapusuzoglu, A. (2012). An empirical analysis of the impact of central bank policy interest rate on the decisions of share investors: evidence from Turkey. Procedia Social and Behavioral Sciences, 62 (2), 489 -493

Jain, B. A., \& Kini, O. (1995). Venture capitalist participation and post-issue operating performance of IPO firms. Managerial \& Decision Economics, 16 (2), 593-606

Kaplan, S. N., \& Lerner, J. (2010). It ain't broke: the past, present, and future of venture capital. Journal of Applied Corporate Finance, 22(2), 36-47 
Katila, J. A., Kim, C., \& Pantzalis, C. (2008). Security analysis, agency costs, and company characteristics. Financial Analysts Journal, 56(6), 54-63.

Kiprotich, F.K (2017). Role of venture capital on the growth of start-ups in Kenya. (Unpublished MBA Thesis), University of Nairobi

Kortum, S. \& Lerner, J. (2000). Assessing the contribution of venture capital to innovation. Journal of Economics, 4 (1), 674-692

Kothari, C. (2004). Research methodology: methods and techniques. In New Age International.

Kovảc, T. \& Vajay, J. (2015). Effects of State-owned and Hybrid Venture Capital Funds in Hungary, Procedia Economics and Finance, 30(2), 430-435.

Kuffman, B. Role of Venture capital financing on Small, Medium, and Microenterprises. Journal of Financial Development, 33(5), 234-253

Lerner, J. (2002). Boom and bust in the venture capital industry and the impact on innovation. Federal Reserve Bank of Atlanta Economic Review 25-39.

Megginson, W., \& Weiss, K. (1991). Venture capitalist certification in initial public offerings. Journal of Finance, 46(3), 879-903.

Memba, F.S. (2015). The impact of venture capital finance in Kenya. (PHD thesis), University of Nairobi

Mitnick, B. (1975). The theory of agency: The policing 'paradox' and regulatory behavior. Public Choice, 24(1), 27-42.

Njoroge, H. (2003). Factors affecting venture capital financing in Kenya. (Unpublished MBA thesis), University of Nairobi

Njumbi, T.W (2018). Factors that Influence venture capital decisions in Kenya. (Ph.D. thesis), Strathmore University

Panwar, A. (2005). Managerial ownership concentration and agency conflict using a logistic regression approach: Evidence from Bursa Malaysia. Journal of Management Research, 1(1), 110.

Pfeffer, H., \& Slancik, K. (1978). The structure of corporate ownership: Causes and consequences. Journal of Political Economy, 93(6), 1155-1177.

Prowse, S. D. (1998). The economics of the private equity market. Federal Reserve Bank of Dallas economic review, Third quarter. Dallas: Federal Reserve Bank

Ross, S. (1973). The economic theory of agency: The principal's problem. American Economic Review, 63(2), 134-139.

Sapienza, H. J. \& Gupta, A. K (1994). Determinants of venture capital firms' preferences regarding the industry diversity and geographic scope of their investments. Journal of Business Venturing, 7(5), 347-362

Sax, C. (2006). Interest Rates and Exchange Rate Movements: Analyzing Short-term Investments in Long-term Bonds [J]. Financial Markets and Portfolio Management. 20 (2), 205-220

Scott, R \& Davis, G. F. (2007). Typology of Organization Theory. 1 ${ }^{\text {st }}$ Edition. Upper Saddle River, NJ, Pearson Prentice Hall.

Subramanian, S.V., Jones, K., Kaddour, A. \& Kriege, N. (2009). Revisiting Robinson: The Perils of Individualistic and Ecological Fallacy. International Journal of Epidemiology, 38(2), 342-360 
Wanjohi, A M. and Mugure, A. (2008). Factors affecting the growth of M SE $s$ in rural areas of Kenya: A case of IC T firms in Kiserian Township, Kajiado District of Kenya. (Unpublished Thesis). The University of Nairobi.

Wooldridge, J. M. (2009). Introductory Econometrics: A Modern Approach. Economic Analysis. 